\title{
Dermatoonkologie: Heutiger Stand und Perspektiven ${ }^{*}$
}

\section{Dermatooncology: Present Status and Perspectives}

Autor

Institut

\section{E. Orfanos}

Campus Benjamin Franklin der Freien Universität Berlin (ehem. Direktor der Universitäts-Hautklinik und Poliklinik)

\section{Bibliografie}

Dol $10.1055 / \mathrm{s}-2008-1077762$

Akt Dermatol 2008; 34:

453-464 (c) Georg Thieme

Verlag KG Stuttgart · New York ISSN 0340-2541

Korrespondenzadresse

Prof. Dr. med. emer.

C. E. Orfanos

Thunerstr.10

12205 Berlin

constantin.orfanos@charite.de

\section{Zusammenfassung}

$\nabla$

Die Dermatoonkologie ist ein relativ junges Teilgebiet der Medizin, das innerhalb der letzten Jahrzehnte eine Schlüsselrolle in unserem Fach eingenommen hat. Die Gründe liegen sowohl im häufigeren Vorkommen von Hautneoplasien in der Klinik, als auch in ihrer Bedeutung als intellektueller Ansatz und Herausforderung für die Forschung. Die Rolle eines Katalysators für diese Entwicklung spielten in Deutschland die 1980 ins Leben gerufene „Kommission Malignes Melanom“ der DDG wie auch die Gründung eines MM-Zentralregisters 1982 in Berlin. Später kam die Gründung der „Arbeitsgemeinschaft Dermatologische Onkologie (ADO)“ dazu.

Die Bedeutung des UV-Lichtes als wichtiges Umwelt-Karzinogen, die geradezu epidemische Ausbreitung von HPV und HIV, die neuen molekularbiologischen Erkenntnisse und der klinische Einsatz diverser anti-Wachstumsfaktoren, von Zyto-

\section{Einfïhrung}

$\nabla$

Kürzlich war in der Tagespresse zu lesen, dass jedes Jahr in Deutschland 430000 Menschen an Krebs erkranken, im westlichen Europa sind es über eine Million. Ein kleiner Teil davon sind bösartige Systemerkrankungen wie Lymphome und Leukämien, ein größerer Teil aber sind solide Krebse, auch solcher der Haut. Mit all seinen Varianten ist der Hautkrebs darunter der häufigste Krebs des Menschen überhaupt. Auf der anderen Seite sind Hauttumoren meist nicht durch allgemeine Beschwerden wie bei bösartigen System-

* Nach einem Vortrag gehalten anlässlich des Symposions „Moderne Aspekte der Dermatoonkologie“ organisiert vom Tumorzentrum und der Klinik für Dermatologie, Venerologie und Allergologie - Immunologisches Zentrum, Städtisches Klinikum Dessau, März 2007. kinen etc., haben eine rasante Entwicklung in der Diagnose und Therapie der wichtigsten Hauttumoren eingeleitet.

Trotz aller Fortschritte stellt die therapeutische Resistenz der Hautneoplasien weiterhin eine Herausforderung für die Zukunft dar. Der Wert der HPV-Vakzination ist abzuwarten, die Tumor-Vakzination blieb bisher enttäuschend. Derzeit erscheinen am ehesten multimodale Gen- bzw. molekulare Ansätze in Verbindung mit klassischen Maßnahmen am besten geeignet, um fortgeschrittene Hauttumoren anzugehen.

Auch die Tumorpräventionsappelle scheinen bisher nur die risikoscheuen Individuen anzusprechen, während die risikofreudigen davon unbeeinflusst bleiben. Vielleicht wird es mittels Aufschlüsselung von Gen-Expressionsprofilen möglich, die jeweiligen Risiko-Kollektive besser erkennbar zu machen und eine gezielte Prävention zu betreiben. erkrankungen gekennzeichnet, sie können früh erkannt werden, sie verursachen keine Verdrängungssymptomatik, sie sind oft klein und nicht besonders auffällig, und haben auch nicht die Akuität entzündlicher Dermatosen. Bemerkenswert ist, dass die Inzidenz nahezu aller Hautkrebs-Varianten in den westlichen Industrieländern während der letzten Jahrzehnte drastisch zugenommen hat, sie hat inzwischen den Charakter einer globalen Hautkrebs-Epidemie eingenommen.

Die Dermatoonkologie ist ein relativ junges Teilgebiet unseres Faches. Hauttumoren haben, zumindest im deutschsprachigen Raum, erst in den letzten Jahrzehnten unsere gezielte Aufmerksamkeit gefunden. Heute hat aber die Dermatoonkologie eine Schlüsselrolle in unserem Fach in Deutschland. 
Wie ist es dazu gekommen und, vor allem, wie ist der heutige Stand?

Die Geburtsstunde der Dermatoonkologie schlug im deutschen Sprachraum, als das maligne Melanom einen rapiden Anstieg seiner Inzidenz in den entwickelten Ländern des Westens zeigte und auf sich aufmerksam machte. Es war gegen Anfang der 70erJahre, eine Zeit, in der die Grundbedürfnisse der dermatologischen Versorgung vor allem durch die Entdeckung und Einführung von Antibiotika und Kortison einigermaßen gedeckt schienen, und man vorsichtig anfing sich mit der Frage des Krebses näher zu befassen. Mir selbst, seinerzeit in Köln, erschien die Häufung maligner Melanome in unserem Krankenkollektiv besonders auffällig. Bemerkenswert war auch, dass die ersten Zytostatika, die damals zur Verfügung standen, wie das frühe Trenimon, das hochwirksame Cyclophosphamid oder später das Chlorambuzil beim Melanom gänzlich versagten, und wir mit BCG-Impfung als Gegenmittel experimentierten. Ab 1978 bestätigte sich auch in Berlin der Eindruck der in den westlichen Bundesländern unstrittig war.

Im Jahre 1980 haben wir somit im DDG-Vorstand die „Kommission Malignes Melanom “ der DDG gegründet, die für die weitere Entwicklung der Dermatoonkologie in Deutschland einen Wendepunkt signalisierte. Je mehr man sich mit der Frage des Melanoms befasste, desto klarer wurden die Bedeutung des Hautkrebses wie auch die Notwendigkeit einer gründlichen Analyse seines gehäuften Auftretens, insbesondere seiner möglichen Induktion durch eine nahezu kultisch betriebene Sonnenlichtexposition in der Bevölkerung.

Das „Zentralregister Malignes Melanom“, das wir im Jahre 1982 an der Berliner Hautklinik der FU gründeten, war ein guter Anfang. $\mathrm{Zu} \mathrm{Beginn}$ befasste sich mit den Daten nur eine kleine Gruppe, vor allem jüngere Kollegen wirkten mit großem Engagement mit, später kamen zur Kooperation mehrere große Hautkliniken dazu. In der Folgezeit bekam das Ganze ein dermatologisches Gesicht, denn zu jener Zeit war die Behandlung des Melanoms eher in den Händen von Internisten und Chirurgen. Als wir 1984/85 die Teilnehmerliste für das Symposium „Malignes Melanom“ des Weltkongresses vorbereiteten, gab es Schwierigkeiten, prominente Experten aus Deutschland als Sprecher zu nominieren. Wenige Jahre später, bei der Organisation des Symposiums „Malignes Melanom“ der DDG in Verbindung mit dem BGA 1989 in Berlin, war die Lage anders. In der Zwischenzeit hatten sowohl die Kommission als auch das Zentralregister Pionierarbeit geleistet.

So rückte allmählich der schwarze Hautkrebs in das Bewusstsein aller Dermatologen ein, die lichtinduzierten epithelialen Tumoren der Haut kamen zwangsläufig dazu, das notwendige „,know how" für dermatochirurgische Tumoroperationen und Chemotherapien wurde erarbeitet, und dermatoonkologische Aufgaben etablierten sich allmählich zu einem wichtigen Bestandteil der dermatologischen Weiterbildung.

Insofern war es eine logische Folge, dass Anfang der 90er-Jahre die Gründung der „Arbeitsgemeinschaft Dermato-Onkologie“ innerhalb der DDG ins Leben gerufen wurde, die heute schon auf ein überaus aktives und erfolgreiches Arbeitspensum zurückblickt. Es besteht kein Zweifel daran, die Dermatoonkologie muss künftig innerhalb unseres Faches und der gesamten modernen Medizin eine überaus wichtige Aufgabe erfüllen.

\section{Die häufigen Hauttumoren $\nabla$}

Die Tumoren der Haut sind im Hinblick auf ihre Herkunft, ihre Häufigkeit und ihr klinisches Verhalten ausgesprochen vielfältig. Die häufigsten davon sind epitheliale Krebse, zu den wichtigsten gehören das maligne Melanom, die kutanen Lymphome und das meist HIV-assoziierte Kaposi-Sarkom. Dazu kommt eine große Vielfalt von Adnex-Tumoren, Tumoren bindegewebigen, vaskulären und neuralen Ursprungs etc., auf die hier nicht eingegangen wird ( $\odot$ Tab. 1).

\section{Tab. 1 Kutane Neoplasien.}

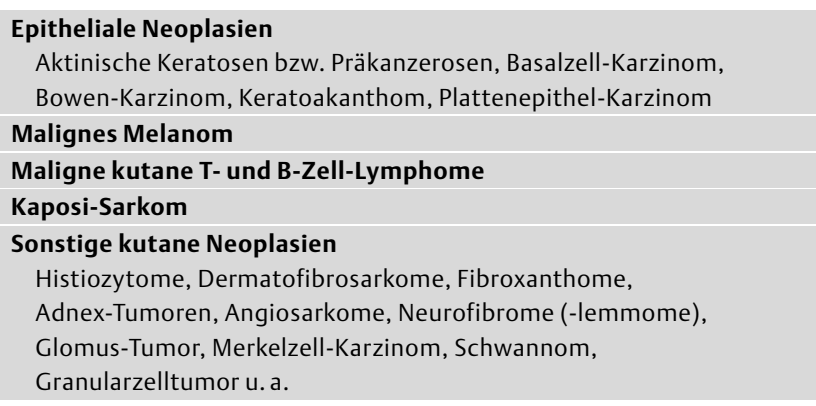

Auch die klinischen Bilder der kutanen Neoplasien zeigen eine eindrucksvolle morphologische Varianz. Fest steht, dass ihre Erkennung und Behandlung das Auge eines erfahrenen Dermatologen, das spezielle Wissen eines Dermatohistopathologen und die therapeutische Erfahrung eines Dermatoonkologen notwendig machen ( $\bullet$ Abb. 1).

Wenn man die Prävalenz und Inzidenz der Hauttumoren betrachtet, so stehen die epithelialen Krebse im Vordergrund. Man könnte sagen sie sind das Standbein der Dermatoonkologie, denn sie rangieren an Häufigkeit an erster Stelle aller Tumoren überhaupt. Die Daten sind approximativ, denn in Australien und im Süden der USA ist die Inzidenz höher, in Europa ist sie etwas günstiger, wobei in nahezu allen Statistiken Männer mehr betroffen sind als Frauen. Die Lymphome sind mit einer geschätzten Inzidenz von immerhin 0,5-1,0/100000 nicht gerade häufig, aber jeder einzelne Fall davon stellt diagnostisch und therapeutisch eine große Herausforderung für den Dermatologen dar. Schließlich, die HIV-assoziierten Kaposi-Sarkome haben in den westlichen Ländern nach der Einführung der hochaktiven antiretroviralen Therapie (HAART) an Zahl abgenommen, doch in anderen geografischen Zonen, wie z.B. in Zentralafrika, sind sie heute ein Hauptkontigent; in mehreren Ländern der Subsahara stehen sie an der Spitze der Top-Ten-Liste aller malignen Tumoren überhaupt ( $\bullet$ Tab. 2).

Pathogenetisch kommt bei einem beachtlichen Teil aller Neoplasien der Haut eine prädisponierte genetische Anlage vor. Als Grund für die Zunahme der Inzidenz kommen dazu

- unsere immer höhere Lebenserwartung,

- unser Freizeitverhalten mit einer durchschnittlichen Sonnenexpositionsdauer, die in den letzten Jahrzehnten durch den zunehmenden Wohlstand immer länger wurde,

- der Klimawandel, mit den dramatischen Veränderungen der Erdatmosphäre durch die erhöhte Gasabgabe von Autos und Industrie, die zur Minderung der Ozonschicht und Erhöhung des UV-Anteils geführt hat, und schließlich 

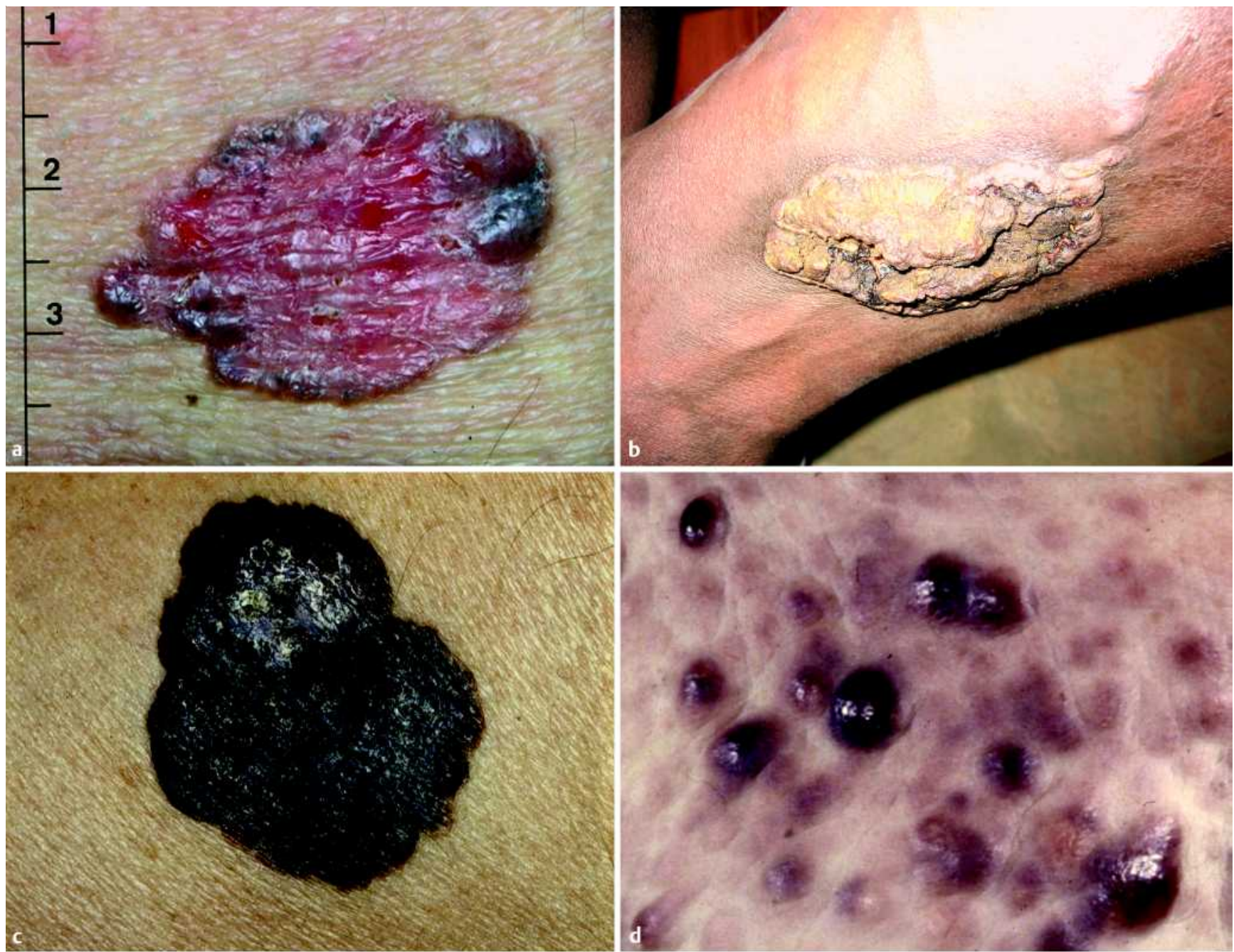

Abb. 1 Die häufigsten Hauttumoren: Basalzellkarzinom (a), Plattenepithelkarzinom (b), malignes Melanom (c), und kutanes T-Zell-Lymphom (Mycosis fungoides, Tumorstadium) (d).

Tab. 2 Häufigkeit von Hauttumoren.

Aktinische Keratosen/Präkanzerosen
bei $10-20 \%$ d. Männer $>40 \mathrm{~J}$.
bei $5-10 \%$ d. Frauen $>40 \mathrm{~J}$.
Basalzell-Karzinom > 100/100 000
Plattenepithel-Karzinom ca. $20-30 / 100000$
Malignes Melanom
Europa $10(-12) / 100000$
USA, Australien 20 bis > 40/100 000
Kutane Lymphome
$0,5-1,0 / 100000$
Kaposi-Sarkom
Z.Z. $2-5 \%$ d. infizierten Männer in Europa, bis zu $30 \%$ aller
HIV-Infizierten in Afrika

- andere karzinogene Noxen aus unserer Umwelt, wie z.B. Infektionen mit onkogenen HPV, immunsuppressive Medikamente, Immunopathien, Organtransplantationen, beruflicher Kontakt mit Teeren, Arsen, usw. Insofern steht heute die Dermatoonkologie im aktuellen Fokus vieler moderner Entwicklungen und ist ein wichtiger Teil unserer modernen Medizin (ब Abb. 2).

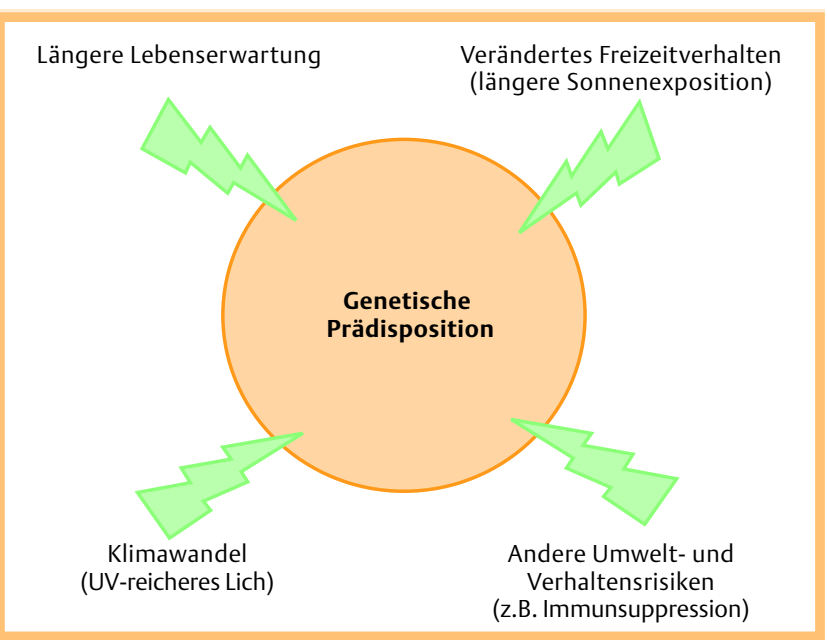

Abb. 2 Ursächliche Faktoren für die Häufigkeitszunahme epithelialer und melanozytärer Hauttumoren. 


\section{Epitheliale Krebse \\ $\nabla$}

Plattenepithel-Karzinom

Bei den epithelialen Tumoren ist die vermehrte Lichtexposition der wichtigste karzinogene Faktor. Dazu kommen humane Papillom-Viren (HPV), die die Rolle eines onkogenen Promoters übernehmen, sowie erworbene Defekte der Tumorimmunabwehr bzw. Immunsuppression, etwa im Rahmen von Organtransplantationen oder einer HIV-Infektion, die zum gehäuften Auftreten führen. Nach Organtransplantationen treten epitheliale Krebse $200 \times$ häufiger als sonst, und verlaufen aggressiver. Insofern sind die epithelialen Krebse zu einem großen Teil auf unseren "lifestyle“, d.h. auf unsere moderne Lebensweise und damit auch unsere Verhaltensfehler zurückzuführen.

Durch die aktuellen Fortschritte in der molekularen Genetik sind bei den epithelialen Tumoren genetische Defekte als Modell in den Vordergrund gerückt, die mit dem gehäuften Auftreten von Hautkrebs vergesellschaftet sind, oder sein Auftreten begünstigen. Genetische Mutationen auf der einen Seite und verhaltensbezogene Risikofaktoren auf der anderen können zu einem Hautkrebs führen, wobei ihre Kombination das Risiko deutlich erhöht. Bei den genetischen Defekten mit Hautkrebsrisiko handelt es sich um - Defekte der DNS-Reparatur (NER; ERCC 1),

- Mutationen in der Tumorüberwachung, d.h. von Genen, die als Tumor-Suppressoren wirken (p16, p53, PTCH), oder

- Defekte von Enzymen der Melaninsynthese (TYR, TRP-1),

die der Haut Schutz gegenüber dem UV-Licht gewähren.

Der entscheidende Faktor bei den epithelialen Tumoren ist zweifellos die Photokarzinogenität des UV-Lichtes, die überlebensfähige transformierte Keratinozyten erzeugt und klinisch aktinische Keratosen als Krebsvorläufer entstehen lässt. Sowohl UVB/UVC direkt, aber auch UVA indirekt, über die entstehenden Radikale, führen zu DNS-Schäden, und über ihre Photoprodukte zu genetischen Mutationen. Beispiel ist das CDKN2A Gen, das für die genetische Stabilität verantwortlich ist. Es kommt zu genotypischen Veränderungen einerseits von $p 14, p 16$ und beim $p 53$, die die genetische Stabilität der epithelialen Zellen überwachen, und vom $B$-Raf, das beim Melanom möglicherweise als Onkogen wirkt.

Nicht zuletzt sieht es so aus, dass es bei manchen epithelialen Krebsen zu einer Interaktion von Licht mit vorhandenen Subtypen von Papillomviren kommt, mit dem Ergebnis einer kombi- nierten onkogenen Mehrschritt-Kaskade. Nach der Inaktivierung des p53 führt die Aktivierung des bak im HPV-Promoter dazu, dass die lichtgeschädigten, HPV-infizierten Keratinozyten weiter proliferieren und überleben. Wichtig für den Dermatologen ist, dass die onkogenen Papillom-Viren sexuell übertragen werden, sodass die anogenitalen Schleimhäute betroffen sind. Grob gerechnet beträgt die jährliche Inzidenz-Zunahme für die Licht- + HPV-induzierten Akanthomen weltweit über 6\%, für die Plattenepithel-Karzinomen ca. 4-6\% und für die malignen Melanome ca. 3-5\%.

Gehen wir nun zu den drei wichtigen klinischen Genodermatosen als Beispiele über, die mit epithelialen Krebsen einhergehen: Beispiel 1: Ein genetisch determiniertes Syndrom ist ein Defekt der DNS-Reparatur, eines Systems mehrerer Enzyme (NER, Nucleotide Enzyme Repair mechanism), die Segmente UV-geschädigter DNS herausschneiden und damit lichtinduzierte Zelldefekte reparieren kann. Die Störung dieses komplexen Mechanismus ist im Einzelnen sehr vielfältig. Der Defekt kann beispielsweise dazu führen, dass die UV-geschädigte DNS nicht erkannt wird, zum anderen kann ein Defekt bei den Helikasen oder Endonukleasen liegen, die das betroffene DNS-Segment entwinden und herausschneiden. Das klinische Äquivalent ist das Xeroderma pigmentosum $(X P)$, das bei uns recht selten ist, in anderen Gegenden aber, z.B. in Zentral-Ostafrika, häufiger vorkommt. Die XP-Patienten müssen mit hohen Lichtschutzfaktoren vor dem Sonnenlicht geschützt werden, denn sie entwickeln frühzeitig Basaliome, Plattenpithel-Karzinome und (seltener) auch Melanome. Während meiner Tätigkeit in Tansania habe ich mehrere Fälle eines XP gesehen und hatte den Eindruck, dass neben den keratinozytären auch melanozytäre Dysplasien bei afrikanischen Patienten häufig vorkommen ( Abb. 3).

Beispiel 2: Ein zweiter, mit erhöhtem genetischem Krebsrisiko behafteter Defekt betrifft das PTCH-Gen, das in chromosomaler Position $9 q$ 22.3-q31 lokalisiert ist, und über das transmembranöse SMO-Protein die Genexpression kontrolliert. Im Falle von PTCH-Mutationen werden Signale gesendet, die schließlich ein Tumorwachstum begünstigen. Die Entkoppelung von SMO aus seiner Kontrolle führt zu Daueraktivierung von Wachstumskaskaden und schließlich zum Krebs, Die Mutation manifestiert sich klinisch mit dem familiären Auftreten multipler BasalzellKarzinome, das sog. Gorlin-Goltz Syndrom.
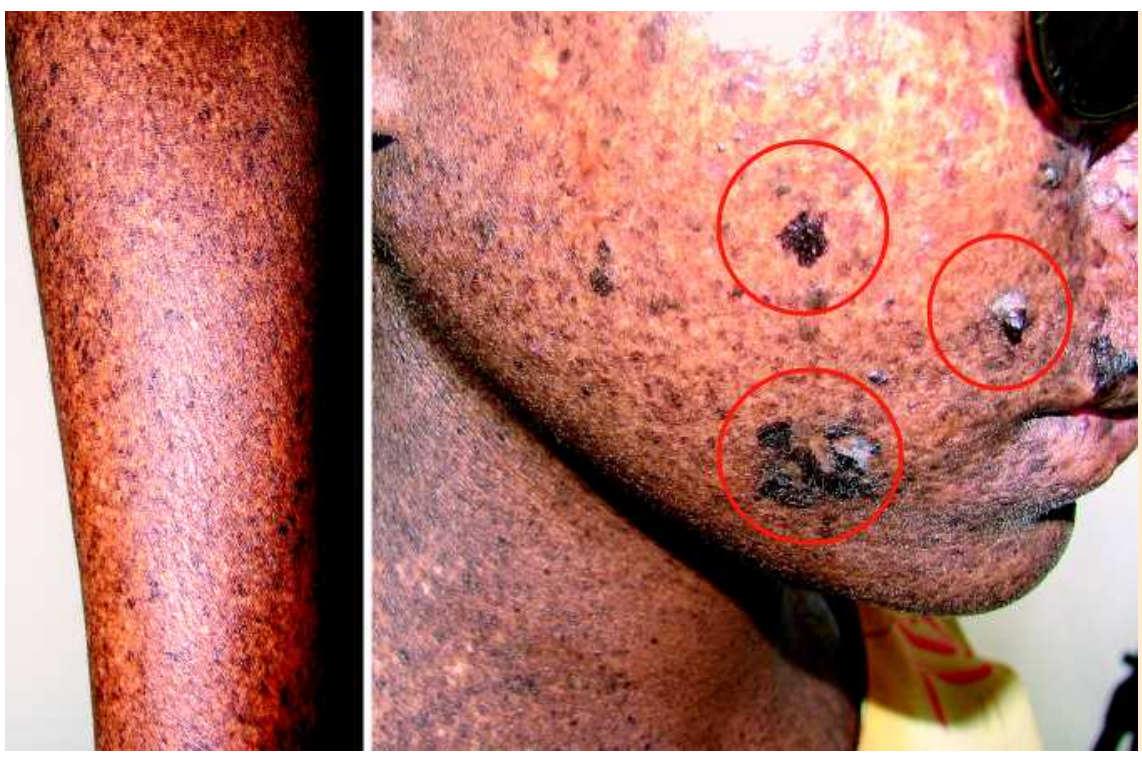

Abb. 3 Xeroderma pigmentosum. Autosomal rezessiv (Prävalenz: 3:1000000); genetische Defizienz der Nucleotide-Excision-Repair (NER; 7 verschiedene Gruppen A-G) führt in Verbindung mit Lichtexposition zum Auftreten zahlreicher epithelialer und melanozytärer Anomalien bzw. Tumoren (Kreise). 
Beispiel 3: Ein dritter genetische Defekt, der zu epithelialen Tumoren führt, ist schließlich der okulokutane Albinismus, eine Erkrankung, die aufgrund eines Defekts der Tyrosinase und des TRP-1 zum Fehlen eines vollwertigen Melanins als UV-Filter führt und ein hohes Risiko für aktinische Schäden und epitheliale Tumoren mit sich bringt. Es gibt verschiedene Varienten, besonders eindrucksvoll ist die höhere Prävalenz des okulokutanen Albinismus (OCA) von OCA 2-Typ bei den zentralafrikanischen Bantuvölkern, und die unglückliche Situation dieser Menschen, die in einer UV-reichen Umwelt leben müssen, ist für die betroffenen Populationen ein großes Problem der ärztlichen Versorgung. Die Lebenserwartung der über 100000 Albinos in Zentralafrika ist aufgrund invasiver Karzinome aller Art um 10 - 15 Jahre kürzer als die des durchschnittlichen Afrikaners in der Region.

Wenn man die genetische Tumorüberwachung am Epithel zusammenfasst, so ist das PTCH-Gen für die genetisch determinierten und das p53 für die UV-induzierten Schäden der DNS verantwortlich. Das proapoptotische $p 53$-Protein ist im Zellkern lokalisiert, überwacht die DNS-Schäden und eliminiert laufend die UV-geschädigten Keratinozyten, sog. „sunburn-cells“, vermutlich auch solche, die von eingeschleusten onkogenen HP-Viren infiziert und bereits transformiert sind. Erst bei wiederholter Reinfektion und längerer Bestandsdauer ist mit dem Überdauern von DNS-Schäden und dem Fortbestehen transformierter Keratinozyten zu rechnen. Mit anderen Worten, UV-induzierte Schäden können über das p53 und das NER-System repariert, die Mutationsvarianten aber sind an sehr vielen und verschiedenen Stellen lokalisiert, womit eine Reparatur der genetischen Codes praktisch unmöglich erscheint.

\section{Malignes Melanom}

$\nabla$

Das Melanom gilt heute uneingeschränkt als ausgesprochener „Wohlstands-Tumor“, der Tumor einer Wohlstandsgesellschaft, die in der zweiten Hälfte des 20. Jahrhunderts den „Urlaub“, die Begriffe „Spaß“ und „Freizeit“ zum gesellschaftlichen Dogma erhoben hat. Die durchschnittliche Sonnenexpositionsdauer in der Bevölkerung nahm gewaltig zu, und die durch UV-Licht induzierten Mutationen des B-Raf werden mit dem malignen Melanom in Verbindung gebracht. Immerhin, bei $20 \%$ der Pigmentzellnaevi von Erwachsenen und bis zu 70\% aller Melanome sind B-Raf-Mutationen nachweisbar.

Die nun über mehrere Jahrzehnte andauernde Zunahme der $\mathrm{Me}$ lanom-Inzidenz ist für die gesamte medizinische Versorgung von Bedeutung, zumal sie bis heute ungebrochen bleibt. In den europäischen Ländern dürfte die Häufigkeit des Tumors insgesamt die Grenze von durchschnittlich 10/100000 deutlich überschritten haben, steigende Inzidenzen werden inzwischen auch aus dem mediterranen Raum berichtet, etwa aus Griechenland und Malta. Die Daten für die USA und Australien sind ohnehin $2 \times$ bis $4 \times$ so hoch, oder gar noch höher. Mit seiner engeren Beziehung einerseits zur Genetik und andererseits zu unserem „lifestyle“ beschäftigt das Melanom nicht nur Dermatologen, sondern auch Genetiker, Epidemiologen, Onkologen, Pharmakologen, Molekularbiologen, Sozialmediziner und viele andere Forscher unterschiedlicher Fachrichtungen.

Epidemiologisch ist die Beziehung des malignen Melanoms zur Lichtexposition nicht so klar und nicht so direkt wie bei den epithelialen Krebsen. Die Bedeutung der Photokarzinogenität bei prädisponiertem Hauttyp ist auch beim Melanom zwar unstrittig, doch eine allgemeine und klare Abhängigkeit des Auftretens maligner Melanome an den Sonnenexpositionsstellen bzw. von der Sonnenexpositionsdauer konnte bisher statistisch nicht belegt werden. Wir wissen, dass neben dem genetischen auch ein Verhaltensrisiko besteht ein Melanom zu entwickeln, und dass, wenn beide Voraussetzungen zusammen vorliegen, das lebenslange Risiko an Melanom zu erkranken fast $100 \%$ ist. Dennoch bleibt vieles noch ungeklärt.

Wie auch immer, durch seine

- klinischen Beziehungen zur Sonnenexposition

(vor allem bei hellhäutigen Kaukasiern),

- sein hohes metastatisches Potenzial und

- seine ausgesprochene Chemoresistenz

kommt dem malignen Melanom eine große Bedeutung in der ärztlichen Versorgung zu.

Wichtig ist dabei, dass der Tumor ex ovo entstehen oder aber auf dem Boden von Vorläufer-Läsionen, wie kongenitale Naevi oder auch (seltener) blaue Naevi auftreten kann. Ex-ovo-Läsionen, wie das SSM, findet man eher bei jüngeren Individuen und Erwachsenen im mittleren Alter, demgegenüber kommen Melanome auf Vorläufer-Läsionen, wie das $L M M$, eher in höherem Alter vor. Bei den genetisch vorbelasteten Personen, wie beim Dysplastischen Naevus-Syndrom (DNS), tritt das Melanom am frühesten auf. Dabei ist es entscheidend, dass der Tumor in den ersten Phasen seiner Umwandlung von einem Pigmentmal in einen Tumor vom Arzt erfasst wird, auch wenn er noch so klein ist, denn die Metastasierung erfolgt sehr früh ( $\bullet$ Abb. 4).

Der unterschiedlichen Entstehung des Tumors entsprechend ist das biologische Verhalten der einzelnen Melanome recht unterschiedlich, vielfach hat man den Eindruck, dass es sich dabei um polyklonale Tumoren handelt, deren klinische Verlauf unterschiedlich ist.

Die Bemühungen des Dermatoonkologen um ein besseres Management des Melanoms haben dazu geführt, dass Techniken gesucht, entwickelt und verfeinert wurden. Sie haben mitgeholfen, die Diagnose zu verbessern, die Prognose genauer abzuschätzen und mittels regelmäßiger Nachsorge die Patienten effektiver zu betreuen. Zum heutigen Stand gehört vor allem das 1992 von Morton eingeführte Konzept der „sentinel node biopsy“ als Möglichkeit den Status der regionalen Ausbreitung des Tumors präzise zu erfassen. Dieses relativ simple und kostengünstige Verfahren ist von erheblicher prognostischer Bedeutung und hat inzwischen weitergehende aufwendige operative Verfahren wie die elektive Lymphadenektomie endgültig verdrängt.

Wichtig erscheint mir dieses Verfahren auch, weil wir mithilfe der histologisch-histochemischen und immunhistochemischen Aufarbeitung der Wächter-LK und der Darstellung von Einzelzell-Metastasen im Lymphknotengewebe unsere Vorstellungen über das metastatische Potenzial des Tumors schärfer definieren konnten. Man war erstmalig in der Lage, die Art und Weise der zellulären Mikrometastasierung des Melanoms im Rahmen seiner lymphogenen Invasion sichtbar zu machen und besser zu verstehen. Während man in den meisten Fällen eine durchaus nennenswerte peritumorale Abwehrreaktion in der Haut nachweisen kann, ist die Situation im regionären Lymphknoten anders: Die Metastasierung erfolgt zunächst über das subkapsuläre Gewebe, wobei die malignen Zellen offenbar nicht als solche erkannt werden und ohne jeden Widerstand unbehelligt in das Parenchym des Lymphknotens eindringen.

Interessant finde ich die Hypothese, dass die regionären Lymphknoten mit ihrem gefäßreichen subkapsulären Stroma, wo die Melanomzellen sich zunächst einnisten, eine Inkubator-Rolle für die entarteten Zellen übernehmen, sodass über die lympho- 


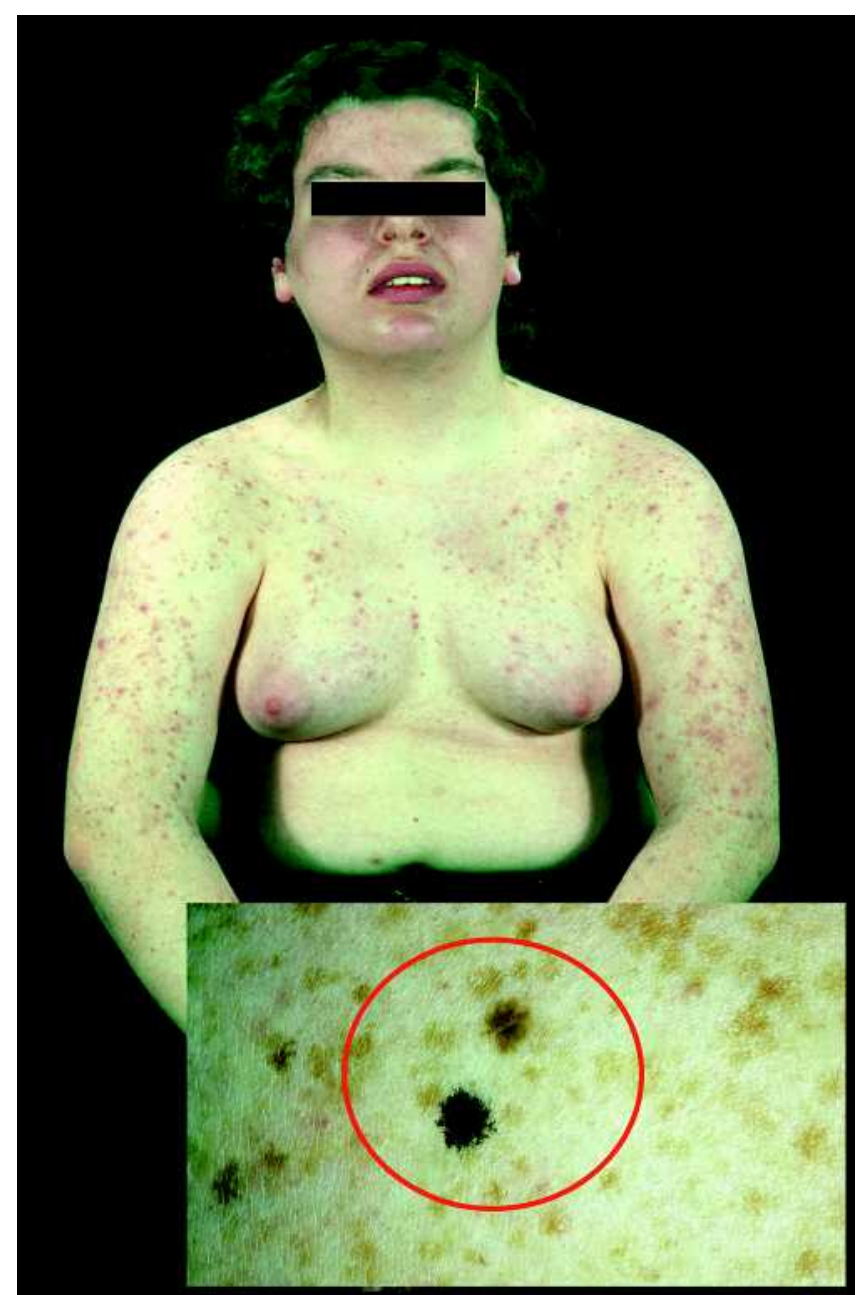

Abb. 4 Das Vorhandensein multipler Pigmentflecken beim familiären dysplastischen Naevussyndrom (> 50 Naevi) als Marker eines genetischen Risikos in Verbindung mit dem Verhaltensrisiko (verlängerte UV-Exposition) sind die zwei wichtigsten tumorigenen Faktoren beim malignen Melanom.

gene oft eine weitere hämatogene Metastasierung des Tumors stattfindet. Wir wissen heute, dass auch sehr dünne Melanome recht früh diesen Weg bestreiten können, etwa 5-6\% aller Melanome mit einer Tumordicke von $<1 \mathrm{~mm}$ zeigen bereits Mikrometastasen im regionären Wächterlymphknoten.

Mithilfe melanomspezifischer Zielgene ist es heute möglich solche Mikrometastasen, sei es durch die Situ-Hybridisierung oder die PCR, im Gewebe oder im Blut zu erfassen. Die prognostische Bedeutung der PCR bzw. der quantitativen (real time) PCR zum Zwecke des Nachweises von Melanomzellen im Gewebe, in Lymphknoten oder anderen Organen, ist in ihrer Bedeutung nicht genau erforscht und somit nicht gänzlich etabliert. Eine Ultraschalluntersuchung der Lymphkoten, auch wenn sie mit den modernsten Techniken durchgeführt wird, kann jedenfalls die immunhistochemische und die PCR nicht ersetzen. Diverse Tumormarker wie MIA, S100ß-Protein u.a. können zur besseren Einschätzung des klinischen Verlaufs beitragen, wenn auch ihre therapeutische Relevanz in den späten Metastasierungsstadien gering ist.

Im Hinblick auf die Behandlung des malignen Melanoms sind die Modalitäten, die uns heute zur Verfügung stehen, vielfältig, und können hier nicht im Einzelnen ausgeführt werden. Die Hoffnungen auf eine effektive Behandlung des metastasierenden Tumors wurden bisher trotz aller Bemühungen nicht erfüllt. Von einer realen Gentherapie sind wir sehr weit entfernt, wenn man bedenkt, dass die Melanogenese von 120 Genen oder mehr reguliert wird. Die Forschung hat aber von all den Bemühungen der letzten 10-15 Jahre erheblich profitiert, und neue Wege wurden eröffnet. Der Einsatz des alpha-Interferon in Verbindung mit Dakarbazin und einige wenige andere Zytostatika hat einen bescheidenen Vorteil gebracht, die Ergebnisse neuerer Studien stehen noch aus. Ob daraus ein erfolgreicheres, für den kranken Menschen vorteilhaftes Schema herauskommen wird, im Vergleich zu den bisherigen, bleibt die Frage.

Eine vorläufige Beurteilung der neuen Ansätze zeigt, dass manche gesetzte Hoffnungen für die Zukunft berechtigt sind. Dazu gehören die Zuhilfenahme proapoptotischer Mechanismen, einer Hemmung von Signalkaskaden, wie die der MAP-Kinasen und der Angiogenese, sowie die Fokussierung auf das hohe metastatische Potenzial des Tumors und die Tumorinvasion. Alles in allem hat es den Anschein, dass keine der bisher angegangenen experimentellen Wege allein zum Ziele führt, nämlich die Eliminierung des Tumors; es zeichnen sich aber multimodale Mehrschritt-Therapieschemata kombinierter zytostatischer und biologischer Chemotherapien ab, die für den Patienten einen Vorteil bringen könnten.

In der aktuellen Melanomforschung wird viel daran gearbeitet, um die Frage der frühen Ausbreitung des Tumors mittels moderner Techniken und spezifischer Melanommarker näher zu beleuchten und prognostische Merkmale auf molekularer Ebene zu definieren, wie Genpolymorphismen, verantwortliche Onkogene, epigenetische Regulation von Tumorsuppressorgenen bzw. die Proteomik, mit der denkbaren Möglichkeit, dass posttranslationelle Proteine für die Metastasierung und Progression des Melanoms verantwortlich sein können. Protein- und Genexpressionsprofile (Genotypisierung) gehören dazu, doch ein Licht im Tunnel der ungewöhnlichen Umstände der frühen Melanom-Metastasierung ist heute noch nicht in Sicht. Merkmale wie das p53, das p16 und einzelne Mitglieder der bcl-2 Gruppe wie das Bax können jedenfalls heute immunhistologisch dargestellt und eine gewisse Aussage über die Prognose kann getroffen werden.

\section{Maligne kutane Lymphome}

$\nabla$

Die malignen Lymphome der Haut, vor allem diejenigen vom T-Zell-Typ, die ca. 65-70\% des Gesamtkollektivs ausmachen, waren und sind noch heute eine große Herausforderung für den Dermatologen. Dabei war seit jeher das Konzept einer heterogen entstehenden, chronisch verlaufenden entzündlichen Reaktion, die nach längerem Bestehen in eine monoklonale Proliferation von einzelnen Lymphozyten-Populationen einmündet, ein wichtiger gedanklicher Ansatz. Die betroffenen LymphozytenPopulationen sind dann genotypisch verändert, zeigen Translokationen und diverse z.T. spezifische Antigene, Onkogene, virale Sequenzen, etc. werden in den Tumorzellen exprimiert. Dementsprechend ist die pathogenetische Basis für die Entstehung maligner Lymphome sehr unterschiedlich ( $\bullet$ Tab. 3).

Im Gegensatz zu früher, als ausschließlich Pathologen und Internisten sich allein für diese Tumoren verantwortlich fühlten, sind heute auch Dermatologen an ihrer Erforschung und Klassifizierung in hohem Maße beteiligt. Sie können das klinische Bild an der Haut genauer einordnen und die Verläufe registrieren. Nicht zuletzt dadurch war es möglich, eine Reihe von klinischen Entitäten genauer herauszuarbeiten und mittels Immunhistologie, 
Tab. 3 Faktoren, die die Entstehung kutaner T- oder/und B-Zell-Lymphome fördern bzw. auslösen.

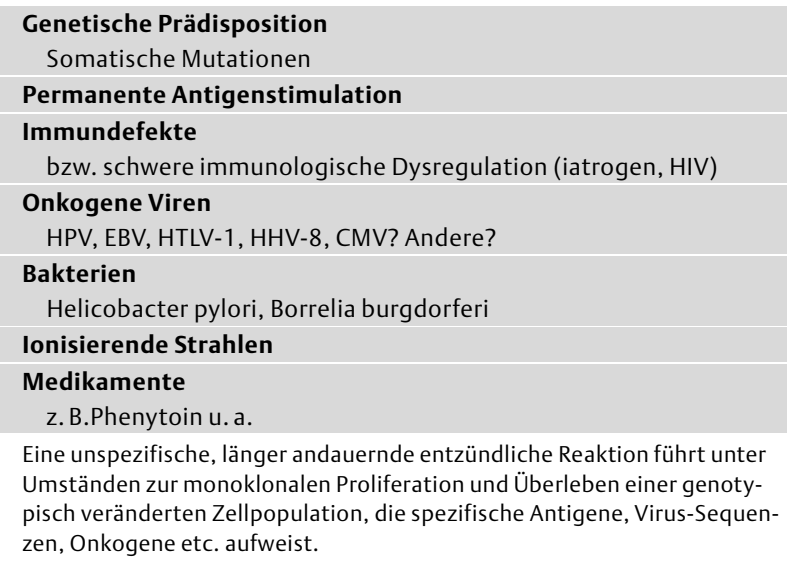

Tab.4 Klinikadaptierte EORTC-WHO Klassifikation der kutanen T-Zell-Lymphome.

Mycosis fungoides (MF)
Follikulotrope MF
Pagetoide Retikulose
Granulomatöses elastolytisches Lymphom
Sézary Syndrom (SS)
Akute T-Zell-Leukämie/Lymphom
CD 30+ T-Zell-Lymphom
Anaplastisches, großzelliges Lymphom
Lymphomatoide Papulose
Panniculitis-ähnliches T-Zell-Lymphom
Peripheres T-Zell-Lymphom vom nasalen Typ
Nicht spezifiziert
Aggressive, epidermotrope CD8+ T-Zell-Lymphome,
$\gamma / \delta$ T-Zell-Lymphome, CD4+ klein- bis mittelgrosszellige,
pleomorphe T-Zell-Lymphome, u. a.

PCR und Klonalitätsuntersuchungen die Lymphom-Diagnose zu verfeinern. So gelang es, eine Klassifikation der vielfältigen Lymphom-Varianten aufzustellen, die zum einen (a) die zytologische Herkunft der proliferierenden Zellpopulation und ihr Verhalten im Gewebe berücksichtigt, und zum anderen (b) diagnose-, therapie-, und prognoserelevant ist, damit sie für die Betreuung der Patienten herangezogen werden kann. Man kann sagen, dass der bisherige Dauerdisput um eine klinisch relevante Richtschnur bei den T- und B-Zell-Lymphomen mit der neuen EORCT-WHOKlassifikation eine einigermaßen befriedigende Antwort fand, und in der Routine heute die notwendige Akzeptanz findet. Das letzte Wort darüber wurde sicher noch nicht gesprochen, zumal das Aufzählen klinischer Entitäten gelichtet wird, wenn wir therapeutisch weiter gekommen sind ( $\checkmark$ Tab. 4).

Im Hinblick auf die Behandlung der kutanen Lymphome scheint sich grundsätzlich zu bestätigen, dass stadienadaptierte Therapien eher vorzuziehen sind, da primär aggressive Schemata, die oft in den USA Verwendung fanden, keine Vorteile bringen. Die Lymphome sind heute eine Domäne moderner molekularbiologischer Ansätze geworden, wobei die kombinierten Verfahren, etwa das alpha-Interferon in Verbindung mit PUVA oder extrakorporaler Photophorese (ECP), also alpha-PUVA oder alpha-ECP, zum Teil in Verbindung mit Retinoiden (Acitretin, Bexaroten), die Standards sind. Das gilt vor allem für die Routinebehandlung des klassischen kutanen T-Zell-Lymphoms (Mycosis fungoides und Sézary-Syndrom).
Tab. 5 Neuere molekulare Optionen für die Behandlung kutaner B- und T-Zell-Lymphome.

\begin{tabular}{|c|c|c|}
\hline Rituximab & (anti-CD $20 \mathrm{MoA}$ ) & Mabthera ${ }^{\circledR}$ \\
\hline Imatinib & (Tyrosinkinase inhibitor) & Glivec $^{\circledR}$ \\
\hline Cetuximab & (anti-EGFrec MoA) & Erbitux $^{\circledR}$ \\
\hline Bortezomib & (26S proteasome inhibitor) & Velcade $^{\circledR}$ \\
\hline Alemtuzumab & (anti-CD $52 \mathrm{MoA})$ & MapCampath ${ }^{\circledR}$ \\
\hline Vorinostat & (HDAC inhibitor) & Zolinza $^{\circledR}$ \\
\hline Tanolimumab & (anti-CD 4 MoA) & \\
\hline
\end{tabular}

Ein therapeutischer Durchbruch bei der Behandlung der malignen Lymphome der Haut ist bisher sicher nicht gelungen, es gibt aber eine Reihe molekularer Perspektiven, die neue Möglichkeiten für die Zukunft eröffnen, etwa auf dem Wege gezielter Interventionen (sog. „targeted therapies“):

Beim kutanen B-Zell-Lymphom mit spezifischem Antigenprofil sind eine Reihe monoklonaler Antikörper bereits im Gebrauch (৫ Tab.5).

Dazu gehören unter anderem das Rituximab (Mabthera $\left.{ }^{\circledR}\right)$, ein anti-CD-20 Molekül, das mit dem Ziel verwendet wird, die Dauer rezidivfreier Intervalle zu verlängern. Auch ein anti-CD-52 Antikörper, das Alemtuzumab (MabCampath ${ }^{\circledR}$ ), wurde bei Mycosis fungoides und Sézary-Syndrom mit zufriedenstellendem Ergebnis getestet und ist auf dem Markt. Repräsentant einer anderen Biomolekül-Gruppe mit breiterem Wirkungsanspruch ist das Imatinib (Glivec $\left.{ }^{\circledR}\right)$. Er gehört zu den neuen Tyrosininkinase-Inhibitoren, die die Signaltransduktionswege blockieren, und sich bei B-Zell-Lymphomen und Leukämien als wirksam erwiesen haben. Neue Präparate aus diesem sozusagen Breitspektrum von Wirkmolekülen sind die Gefinitib (Iressa ${ }^{\circledR}$ ) und Dasanitib $\left(\right.$ Sprycel $\left.^{\circledR}\right)$; vor allem akute lymphatische Schübe und akute Blastenkrisen scheinen darauf gut anzusprechen. Sie sind oral verabreichbar und haben ein relativ günstiges Nebenwirkungsprofil.

Interessant für den Dermatologen ist auch, dass das Imatinib neuerdings auch für das Hypereosinophilie-Syndrom und das Dermatofibrosarcoma protuberans in den Ländern der EU zugelassen ist, deren Signaltransduktionswege als Imatinib-empfindlich erkannt wurden. Auch die systemische Mastozytose scheint auf das Medikament gut anzusprechen. Bei klassischen epithelialen Tumoren hingegen, Plattenepithel-Ca und Mamma$\mathrm{Ca}$, hat Imatinib versagt. Hier werden mehr oder weniger gezielt monoklonale Oberflächenrezeptoren-Blocker verwendet, wie beispielsweise der Her2rec-Blocker Trastuzumab (Herceptin ${ }^{\circledR}$ ) oder der EFGrec-Blocker Cetuximab (Erbitux ${ }^{\circledR}$ ) und, mehr übergreifend, das neue Lapatinib $\left(\right.$ Tykerb $\left.^{\circledR}\right)$ eingesetzt, das an mehreren Stellen gleichzeitig angreift („multi-target“). Bei manchen epithelialen Krebsen liegt offenbar eine kombinierte Mutation der Oberflächenrezeptoren EGFrec und Her-2rec vor, die das Zellwachstum antreibt. Auch der EGF ist letztlich, wie der Her-Rezeptor, Mitglied der erbB-Familie.

Neu ist auch das Bortezomib (Velcade ${ }^{\circledR}$ ), das mit dem 26S Proteasom interferiert und damit die Proteinhomeostase maligner Lymphomzellen, insbesondere solcher mit plasmozytärer Differenzierung, stört. Diese Substanz wurde inzwischen für einige Indikationen zugelassen, einschl. des Mantelzell-Lymphoms, und soll auch bei Mycosis fungoides und Sézary-Syndrom Erfolge in Aussicht stehen. 


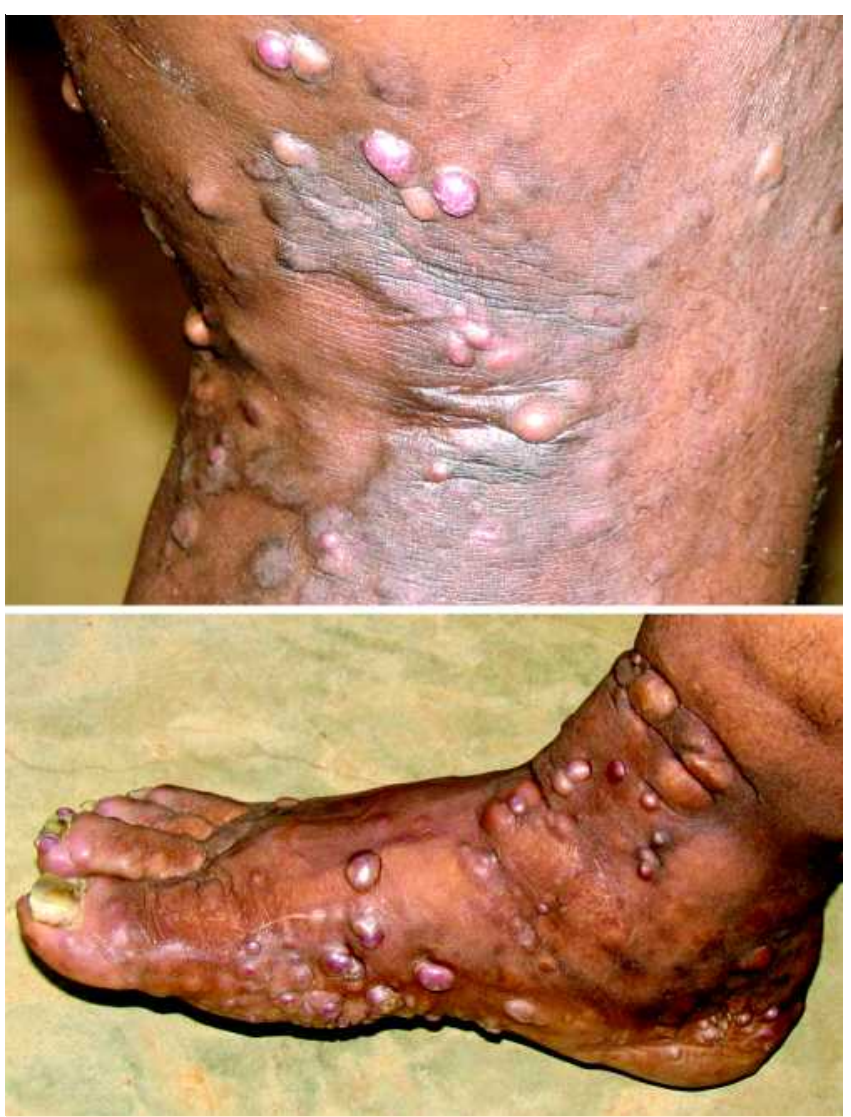

Abb. 5 HIV-assoziiertes, disseminiert plaqueartig und nodulär wachsendes, fortgeschrittenes Kaposi-Sarkom bei einem afrikanischen Patienten (RDTC, Moshi/Tansania).

\section{Kaposi-Sarkom}

Einen besonders eindrucksvollen Fokus dermatoonkologischer Forschung lieferte in den 80er und 90er Jahren das Kaposi-Sarkom, das früher extrem selten war, durch seine HIV-Assoziation aber eine häufige Beobachtung wurde. Durch die Einführung der hochwirksamen antiretroviralen Therapie (HAART) trat das KS im Westen wieder zurück, doch in einigen geografischen Zonen unserer Welt, wie beispielsweise in der Ländern der Subsahara, die durch eine hohe HHV-8 Prävalenz ausgezeichnet und von der HIV-Infektion schwer betroffen sind, ist es immer eine regelmäßige Erfahrung, man könnte sogar sagen, ein nahezu tägliches Problem. Heute wissen wir, dass den europäischen und den afrikanischen KS-Varianten einige klinische Besonderheiten zuzuordnen sind ( $\bullet$ Abb.5), doch hier wird darauf nicht näher eingegangen, da das Kaposi-Sarkom, mit und ohne HIV-Assoziation, einer umfangreichen Ausarbeitung bedarf.

\section{Neue onkologische Behandlungsansåtze} $\nabla$

Ein großes Problem in der Dermatoonkologie ist die therapeutische Resistenz von Hauttumoren, die bis heute nicht unerhebliche Probleme mit sich gebracht hat. Ein besonderer Punkt war erreicht, als man feststellte, dass Hauttumoren auf die konventionellen Chemotherapeutika nicht oder kaum ansprachen. In den 70er und 80er Jahren kamen zahlreiche Mono- und Polychemotherapien in die klinische Anwendung, doch ein wirklicher Durchbruch blieb aus. Nach all den Bemühungen von über drei
Jahrzehnten stehen wir heute ohne eine wirksame systemische Therapie für den Hautkrebs da, vielleicht mit Ausnahme von nur wenigen Substanzen und dies nur in bescheidenem Maße. So fing man an, sich in den letzten zwei Jahrzehnten mit den drei Fragen zu beschäftigen,

- Was können die eigenen biologischen Mechanismen von Wachstumskontrolle und -überwachung in der Tumorabwehr therapeutisch bewirken?

- Ist es möglich, die Immunreaktion des Tumorträgers so zu stärken oder/und die Antigenität des Tumors so zu steigern, dass ein Tumorwachstum unterbunden oder zumindest eingeschränkt wird?

- Kann man überhaupt den Menschen gegen Krebs immunisieren? Ist eine direkt gegen das Tumorgewebe bzw. die Tumorzellen gerichtete Krebsvakzination ein realistisches Ziel?

Auch wenn heute ein Durchbruch nicht gelungen ist, so wurden auf der Suche nach einer Lösung neue Gen- und molekulare Ansätze erarbeitet und unser potenzielles Arsenal gegen den Krebs wurde erweitert. Gerade durch die Chemoresistenz der Hauttumoren geriet die Dermatoonkologie in die Vorderfront dieser Entwicklung, denn, mit der verbesserten Kenntnis der Eigenschaft der Haut als Immunorgan und der Aufbruchsstimmung in der Biotechnologie, kam es zur Entwicklung wirksamer neuer Pharmaka und Biomoleküle, die neue therapeutische Konzepte ermöglichten. Heute stehen uns eine große Zahl molekularer Behandlungsoptionen zur Verfügung. Nun gilt es sie zu sortieren, und die Strategien genauer auszuarbeiten.

Die möglichen Wege sind konzeptuell denkbar, gebraucht werden Moleküle, die in der Lage sind,

- Rezeptoren onkogener Wachstumsfaktoren zu blockieren, etwa mit Cetuximab (Erbitux ${ }^{\circledR}$ ) z.B. bei Plattenepithel-Karzinomen, vor allem in Kopf- und Halsbereich, wenn der EGFRezeptor überexprimiert ist, oder mit Trastuzumab (Hercep$\operatorname{tin}^{\circledR}$ ) beim Mamma-Ca, wo ein anderes Wachstumssignal, der Her 2-Rezeptor, den klinischen Verlauf mit bestimmt;

- Signalkaskaden, die für das Tumorwachstum notwendig sind, zu unterbinden,

wie die Phosphorylierungs-Inhibitoren, die bei malignen Lymphomen zum Einsatz kommen, etwa mit Ipatinib $\left(\right.$ Glivec $\left.^{\circledR}\right)$, das neue Gefitinib (Iressa ${ }^{\circledR}$ ), etc.;

- die Bildung tumoreigener Gefäßnetze zu bremsen, wie die Inhibitoren des VEGF, deren adjuvante Anwendung bei diversen Malignomen einen Überlebensvorteil verspricht, etwa mit Bevacizumab $\left(\right.$ Avastin $\left.^{\circledR}\right)$, Pegatanib $\left(\right.$ Macugen $\left.^{\circledR}\right)$, Sorafenib (Nexavar $\left.{ }^{\circledR}\right)$ u.a.;

- den Zugang der Tumorzellen in das umliegende Stroma und andere supportive Mechanismen der Tumorentstehung zu erschweren oder zu unterbinden. Schließlich bemüht man sich

- Wege zu finden, um geeignete Medikamente, Gene, Steuermoleküle, die das Tumorwachstum bremsen, direkt in die Krebszelle einzuschleusen.

Derartige Biomoleküle werden meist in Kombination mit Radiotherapien, Chemotherapien, neoadjuvante Schemata etc. eingesetzt, und sind mit einer besseren lokalen Kontrolle und einem mäßigen Überlebensvorteil verbunden. Dazu kommt die Entwicklung neuer Adjuvantien, die die Nebenwirkungen der Chemotherapien einschränken, und die gesetzten Schäden zum Teil reparieren. Diese Entwicklungen (z. B. potente Antiemetika) haben erheblich dazu beigetragen, die Toxizität der Chemotherapeutika in den Griff zu bekommen und unseren Stand zu verbessern. 
Bei allen molekularen Monotherapien gegen Oberflächen-Rezeptoren ist allerdings der Anteil der Versager recht hoch, denn ihre Wirkung ist nur dann überzeugend, wenn der Rezeptor, gegen den sie gerichtet sind, im Tumor überexprimiert wird, was aber nicht immer der Fall ist. Insofern kommen zurzeit die neuen Biomoleküle in den meisten Protokollen mit traditionellen Chemotherapien kombiniert zur Anwendung. Von den epithelialen Tumoren wissen wir allerdings, dass Rezeptoren-Analoga in zytoplasmatischen Innenmembranen existieren, die nicht erfasst werden. Sobald aber der oberflächlich liegende Rezeptor in irgendeiner Weise blockiert oder inaktiviert wird, wandert das Analogon an die Oberfläche und übernimmt als neues Todeskommando die Verantwortung. Das wird beispielsweise beim Her-2receptor angenommen, der ein zytoplasmatisches Pendant, den Her-3receptor, haben soll. Hier findet sozusagen ein „Receptor-replacement" statt, das wir auch aus den onkogenen Viren kennen.

Perspektivisch könnte man überlegen, ob es möglich ist, eine solche zytoplasmatische Rezeptor-Wanderung zu unterbinden. Trifft ein solcher Trick auch für das Versagen anderer Rezeptorenblocker zu? Können, wie angenommen, etwa Antioxidantien, evtl. auf dem Wege einer Stabilisierung der Membranstruktur und ihrer Fluidität, eine günstige Rolle bei der Rezeptorblockade in der Tumortherapie spielen?

Derartige Fragen sind unter anderem in aktueller Diskussion. Werden neue adjuvante, multimodale Chemotherapien einschl. Signalkaskaden-Hammer und Angiogenese-Blocker eine mögliche Lösung für das maligne Melanom sein? Könnten solche kombinierte molekulare Therapien einen Überlebensvorteil für den Patienten bringen? Oder zumindest eine Verlängerung der progressionsfreien Überlebenszeit? Diese Fragen bleiben noch ohne Antwort.

Man muss konstatieren, dass nicht zuletzt die Dermatoonkologie, die sich insgesamt mit nachhaltig Chemotherapie-resistenten Hauttumoren befasst, ein festes Fundament und eine unstrittige ärztlich-ethische Rechtfertigung für die teure Biomedizin geliefert hat, die unser Gesundheitssystem heute finanziell so belastet. Eine Stagnation in der Therapie - wie man manchmal heute behauptet - liegt jedenfalls trotz allem nicht vor, auch wenn man nach all der Mühe über die letzten 20 Jahre etwas enttäuscht sein mag. Die Perspektiven sind gegeben, und das Ziel erscheint zwar nicht nahe, aber zumindest in der Zukunft greifbar. Aus der heutigen Perspektive wird man demnächst in der Krebstherapie multimodale Strategien bevorzugt anwenden, mit denen das neoplastische Geschehen von verschiedenen Seiten und mit mehreren Mitteln angegangen wird.

\section{Tumorvakzination}

$\nabla$

Eine Wunschvorstellung für die Zukunft ist die Tumorvakzination. Ein Teilerfolg zeichnet sich bei den virusinduzierten epithelialen Tumoren ab, wobei hier die Vakzination nicht gegen das neoplastische Gewebe selbst, sondern gegen die onkogenen HPV-Subtypen gerichtet ist, die als potente Krebsinduktoren wirken.

Als klassisches Beispiel dafür gilt das Cervix-Ca. Dieser Tumor interessiert in vielfacher Hinsicht den Dermatovenerologen, da die Übertragung der onkogenen Viren durch sexuelle Kontakte erfolgt, die auch für die Genitalwarzen verantwortlich sind. Die neuerdings eingeführte HPV-Vakzination verspricht gute Ergebnisse für beide: Durch die rechtzeitige Impfung sollen $70 \%$ aller
Cervix-Ca und 90\% aller Genitalwarzen verhindert werden können. Der rekombinante Impfstoff, der auf dem Markt gekommen ist, enthält keine Virus-DNS, es besteht aus dem nicht infektiösen Viruskapsid, und schützt gegen HPV 16, 18, 31, 33, also gegen 4 von insgesamt über 100 Papillom-Virustypen, die als bekannte Onkogene gelten, und eine Assoziation auch zur bowenoiden Papulose zeigen. Dazu wird vom Hersteller auch ein möglicher Schutz gegen HPV 6, 11 angegeben, die für Condylomata acuminata, die Riesen-Kondylome Buschke-Löwenstein und die meisten Genitalwarzen verantwortlich sind. Andere Impfstoffe sind im Anmarsch ( $\odot$ Tab. 6).

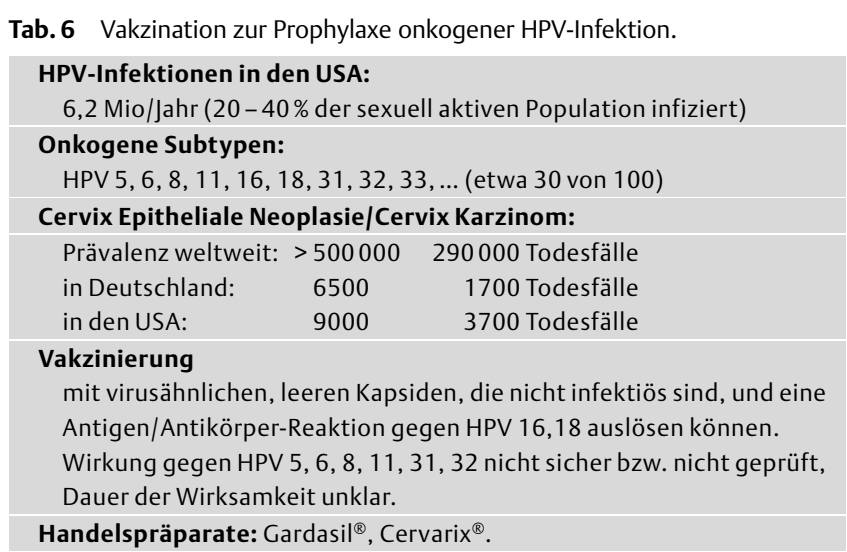

Die ebenso onkogenen HPV 5, 8 (Epidermodysplasia verruciformis) sowie HPV 13, 32 (Fokale epitheliale Hyperplasie Heck) bleiben vorerst draußen vor. Bei nicht infizierten Individuen, also prophylaktisch, sind die Erfolgsaussichten größer, während therapeutisch keine ausreichende Erfahrungen vorliegen. Allerdings ist es nicht klar, ob nach erfolgtem Schutz gegen die HPV 16, 18, 31 und 33, wie auch gegen 6 und 11, evtl. andere Typen an ihre Stelle treten können, etwa im Sinne eines sog. „virus replacement“, denn die diversen HPV-Mitglieder stehen sehr nah zueinander. Ebenso ist es nicht klar, wie lange ein Virusschutz nach erfolgreicher Vakzination voll intakt bleibt. Diverse Impfprogramme werden zurzeit langfristig überprüft. Insgesamt denke ich, dass die Problematik der Virusinduktion epithelialer Tumoren der Haut und Schleimhaut und das Pionierfeld der Tumorvakzination auch den Dermatoonkologen in der Zukunft zunehmend beschäftigen werden. Natürlich wünscht man sich aber mittels Vakzination nicht nur die Prävention, sondern auch die Therapie bestehender Tumoren, einschl. der Vermeidung von Rezidiven. Doch davon sind wir weit entfernt. Bei den Versuchen die Antigenität des Tumors zu steigern war die Frage zu beantworten, welche Peptide auszuwählen? Welche hätten die stärkste Antigenität und wäre es überhaupt sinnvoll, auf diesem Wege eine Elimination des Tumorzellverbandes anzustreben? Wenn wir von den HPV-Vakzinen absehen, so man muss heute feststellen, dass sämtliche Melanom-Vakzine, die bisher in fortgeschrittenen Fällen mit malignem Melanom auf experimenteller Basis zur Anwendung kamen, eindeutig versagt haben (๑ Tab. 7).

Vielfach war es möglich, eine T-Zell-Antwort durch die Tumorvakzinierung zu maximieren, doch in über 1000 Patienten, bei denen insgesamt entsprechende Versuche vorgenommen wurden, blieb ein messbarer klinischer Erfolg bisher aus. Ein nennenswerter Überlebensvorteil ließ sich nicht erzielen, an eine klinische Anwendung ist vorerst nicht zu denken. 
Tab. 7 Vakzinierungsversuche beim malignen Melanom.

Vakzinierung mit melanomassoziierten Peptiden mit Antigencharakter Transfer von bzw. Vakzinierung mit proteinbeladenen, in vitro gezüchteten dendritischen Zellen

Transfer von IL-2-expandierter tumorinfiltrierender Lymphozyten (sog.TILs)

Vakzinierung mit PCR-amplifizieter Tumor-RNS

Vakzinierung mit „nackter“ DNS u.a.

Insbesondere die Erwartungen, die man in die DC-basierte Vakzinierung gesetzt hat, waren $z u$ hoch, das Ergebnis war nach den ersten optimistischen Berichten im Allgemeinen enttäuschend. Möglicherweise spielte beim bisherigen Versagen der Krebsvakzinierungen das Auftreten von Immuntoleranz eine Rolle, vielleicht ist aber auch die Vorstellung, dass eine Tumorantigen-spezifische T-Zellantwort oder eine wie auch immer geartete Population manipulierter dendritischer Zellen allein einen bereits ausgewachsenen Tumor zum Einschmelzen bringen kann, einfach überzogen. Denn ein echtes ,immune escape“ des Tumors findet ohnehin nur in seltenen Fällen statt: In der Regel findet sich ja eine Immunreaktion um den Tumor herum, diese reicht aber allenfalls aus, um die Tumorausbreitung eine Zeit lang in Schach zu halten. Eine Tumoreliminierung findet beim ausgewachsenen Tumor selbst bei stärkster Abwehrreaktion nicht statt, nur transformierte Zellen zu Beginn ihrer Entwicklung werden von einer intakten Immunabwehr eliminiert. Das heißt, die neoplastische Transformation der Zelle bedeutet eo ipso, dass gegen diesen Gegner die Abwehr nicht ausreicht, oder gar versagen muss.

Die Vakzinierung gegen die onkogenen humanen Papillom-Viren ist auch nur dann erfolgreich, wenn eine frühe Vakzinierung, möglichst vor dem Auftreten der Infektion, erfolgt, und nicht etwa wenn ein ausgewachsenes Cervix-Ca bereits vorhanden ist. Bei derartigen Versuchen wäre es sinnvoller, zusammen mit der Stärkung der zellulären Abwehr auch andere Parameter zu berücksichtigen, wie $z$. B. das begleitende und überaus wichtige Stroma.

\section{Perspektiven: Frühdiagnose und Tumorprävention $\nabla$}

In Anbetracht dessen, was wir bisher erreicht haben, heißt das Gebot der Stunde Tumorprävention bzw. eine möglichst frühe Diagnose. In dieser Hinsicht beinhalten die Perspektiven der Dermatoonkologie unter anderem den nachvollziehbaren Trend, einen großen Teil dieser Routineaufgaben von den UniversitätsKliniken in spezialisierte Zentren und nicht zuletzt auch in ausgewiesenen Arztpraxen zu verlagern. Neben den forscherischen Aspekten ist die Prävention und Früherkennung onkologischer Hautleiden eine allgemeine Aufgabe des erfahrenen Dermatologen und die Betreuung von Tumorkranken setzt viel Zuwendung und persönliche Betreuung voraus. Gerade für Hauttumoren und bei älteren Kranken eignet sich durchaus eine ambulante Behandlung, die dem Patienten mehr Freiräume lässt.

Eine frühe Prävention und Früherkennung des malignen Melanoms durch geeignete Aufklärungsmaßnahmen von gefährdeten Kollektiven zum lokalen und auch textilen Lichtschutz einschl. der notwendigen Verhaltensmaßnahmen, die dazu gehören, ist weiterhin eine dringende Aufgabe, denn die Aussicht auf Heilung ist mit der rechtzeitigen Entfernung des Primärtumors verbunden.
Bemerkenswert ist, dass trotz aller Bemühungen um Aufklärung der Öffentlichkeit über die notwendigen Maßnahmen zur Prävention des malignen Melanoms noch keine signifikante Minderung seiner Inzidenz bisher bekannt geworden ist. Auch Studien, die den Verbrauch von Lichtschutzmitteln mit der Melanom-Inzidenz oder -Prävalenz in größeren Bevölkerungsgruppen über längere Zeit in Verbindung bringen, stehen nach meiner Kenntnis noch aus. Eine australische Studie bezog sich lediglich auf das Plattenepithel-Karzinom.

Eine intensive Aufklärung über die sonstigen Hauttumoren, die sämtlich gut übersehbar sind, ist zweifellos zu fordern, einschließlich der Implementierung von Maßnahmen, die eine primäre Prävention für potenzielle Patienten schmackhaft machen. Derartige Maßnahmen sind uns aus Australien bekannt. Sie waren durchaus erfolgreich, und zwar in dem Sinne, dass der Schutz vor der Sonnen- und UV-Exposition vor allem in der Kindheit und Jugend rigoros eingehalten wird. Andererseits steht meines Wissens auch hier ein messbarer Erfolg im Sinne einer Minderung der Prävalenz epithelialer Tumoren durch Aufklärungsmaßnahmen noch nicht fest. Möglicherweise ist die Latenzzeit dafür zu kurz. Hier wäre zu überlegen, ob Aufklärungskampagnen nur diejenigen treffen, die das Risiko scheuen, während die Risikofreudigen auf solche Maßnahmen ohnehin nicht reagieren. Ähnliche Überlegungen betrafen auch die Empfehlungen, potente Sonnenschutzmittel verstärkt zu verwenden. Marktforschungen lassen vermuten, dass allenfalls 50\% derjenigen, die aufgeklärt wurden, bereit sind einen intensiven Lichtschutz zu betreiben.

Dennoch, in Deutschland, aber auch in den meisten westlichen Ländern, nimmt der Verbrauch an Lichtschutzmittel deutlich zu, die Zahl der Sonnenstudios nimmt ab, bzw. es ist ein Stillstand eingetreten; der Umsatz soll im Jahr 2005 insgesamt auf 1 Milliarde Euro leicht zurückgegangen sein. Trotz eines deutlichen Rückgangs der Nutzer besuchen aber heute noch immerhin 12,2 Millionen der deutschen Bevölkerung, also ca. 20\% aller Deutschen älter als 18 Jahre regelmäßig Solarien, wobei über $2 / 3$ davon Frauen sind $(71,4 \%)$. Immerhin ist ein Gesetzgebungsverfahren in Vorbereitung, wonach die Nutzung von Solarien für Minderjährige (unter 18 Jahre) verboten werden soll. Inwieweit das alles nutzen wird ist die Frage; in den USA haben bisher alle Appelle der letzten 10-15 Jahre im Hinblick auf die Inzidenzhöhe des Melanoms keine Wirkung gezeigt.

Inwieweit die Einführung von Externa neueren Typs sinnvoll ist, nämlich solcher, die neben den UV-Filtern etwa Radikalfänger enthalten, die endogene DNS-Reparatur reaktivieren oder sie enzymatisch ergänzen, wird die Zukunft zeigen müssen. Es ist nicht nur die Frage, was die Mittel imstande sind zu bewirken, sondern vielmehr, wer sie und wie lange sie anwendet.

Für die Zukunft wäre es wünschenswert, mithilfe von screeninggeeigneten Mutationsmarkern, das individuelle Hautkrebsrisiko frühzeitig erfassbar zu machen. Bei epithelialen Tumoren wäre dies beispielsweise denkbar, durch Darstellung von EGF und p53 oder des in neuerer Zeit näher untersuchten ERCC1 (excision repair cross complement-1) ein solches Risiko näher zu definieren. Damit wäre es möglich, Maßnahmen individuell zu treffen, und die Prävention gezielter auf diejenigen einzuschränken, die wirklich gefährdet sind. Das würde uns in die Lage versetzen, intensive Appelle an die Öffentlichkeit um Aufklärungs- und Präventionsmaßnahmen mit all ihren Folgen besser zu fokussieren. Bei einigen Tumoren sind derzeit Untersuchungen im Gange, Genexpressions-Profile ausfindig zu machen, die als prognostische Marker für das Tumorrisiko und für eine frühe Metastasie- 
rung, bzw. für das Auftreten von Rezidiven, sprechen. Ein progressionsfreies Überleben von Tumorträgern wird hier angepeilt. Der Wissensvorsprung, den uns eine Früherkennung des individuellen Krebsrisikos verschaffen würde, wäre eine große Hilfe, um die Zukunft zu meistern.

\section{Abstract}

\section{Dermatooncology: Present Status and Perspectives} $\nabla$

Dermatooncology is a rather new topic in our specialty; however, it now plays a key role in Dermatology. This applies to the frequent occurrence of skin tumours in our offices and hospitals, but also to its value as an intellectual challenge for experimental skin research. In Germany, the early creation of a Committee „Malignant Melanoma“ of the German Dermatological Society in 1980, and the foundation of a "Central Register Malignant Melanoma“ 1982 in Berlin have been catalytic for this development. Later on, the German „Working Group on Dermatooncology (ADO)" was founded.

The recognition of UV-light as an important environmental carcinogen, the epidemic widespread of HPV and HIV, our updated knowledge in molecular biology, and the clinical introduction of various monoclonal antibodies to growth factors, cytokines etc. have greatly contributed in improving our diagnostic and therapeutic procedures. Nevertheless, the therapeutic resistance of most skin tumours is still a challenge for the future.

While the value of HPV vaccination is still to be elucidated, tumour vaccination has been disappointing. Presently, combined multimodal schedules of gene- resp. molecular agents together with classical antitumour agents represent the most promising modalities for treating progressed neoplasms.

Public actions to implement tumour prevention seem to influence only a part of the public that is prepared to accept light exposure as a risk, while the other remains irresponsive. Possibly, gene- and molecular profiles may enable us to recognise the groups at risk early, and introduce targeted tumour prevention.

\section{Literatur}

1 Ahmed AM, Madkan V, Tyring SK. Human papillomaviruses and genital disease. Dermatol Clin 2006; 24: 157- 165

2 Arenberger $P$, Arenbergova, Gkalpakiotis $S$ et al. Multimarker real-time reverse transcription-PCR for quantitative detection of melanoma-associated antigens: a novel possible staging method. J Eur Acad Dermatol Venereol 2008; 22: 56-64

3 Arenberger P, Arenbergova M, Vorhadnikowa 0, Kremen J. Early detection of melanoma progression by quantitative real-time RT-PCR analysis for multiple melanoma markers. Keio J Med 2008; 57: 57-64

4 Assaf C, Bagot R, Dummer R et al. Minimizing adverse side-effects of oral bexarotene in cutaneous T-cell lymphoma: an expert opinion. $\mathrm{Br}$ J Dermatol 2006; 155: 261 - 266

5 Assaf C, Hummel M, Steinhoff et al. Early TCR-beta and TCR-gamma PCR detection of T-cell clonality indicates minimal tumor disease in lymph nodes of cutaneous T-cell lymphoma: diagnostic and prognostic implications. Blood 2005; 105: 503-510

6 Assaf C, Weichenthal M. Therapie des kutanen T-Zell-Lymphoms. J Dtsch Dermatol Ges 2008; 6: 256-268

7 Brower V. Cancer gene therapy steadily advances. J Natl Cancer Inst 2008; 100: 1276 - 1278

8 Burg G, Kempf W, Cozzio A et al. WHO/EORTC classification of cutaneous lymphomas 2005: histological and molecular aspects. J Cutan Pathol 2005; 32: 647-674
9 Dippel E, Klemke CD, Goerdt S. Current status of cutaneous T-cell lymphoma: molecular diagnosis, pathogenesis, therapy and future directions. Onkologie 2003; 26: 477-483

10 Dummer R, Assaf C, Bagot $M$ et al. Maintenance therapy in cutaneous T-cell lymphoma: who, when, what? Eur J Cancer 2007; 43: 2321 2329

11 Eberle J, Fecker LZ, Hossini AM et al. CD95/Fas signaling in human melanoma cells: Conditional expression of CD95L/FasL overcomes the intrinsic apoptosis resistance of malignant melanoma and inhibits growth and progression of human melanoma xenotransplants. Oncogene 2003; 22: 9131 - 9141

12 Fecker LZ, Geilen CC, Hossini AM et al. Selective induction of apoptosis in melanoma cells by tyrosinase promoter-controlled CD95 ligand overexpression. J Invest Dermatol 2005; 124: 221 - 228

13 Fisher R, Darrow DH, Tranter M, Williams JV. Human papillomavirus vaccine: recommendations, issues and controversies. Curr Opin Pediatr 2008; 20: $441-445$

14 Forsea AM, Müller C, Riebeling $C$ et al. Nitrogen-containing bisphosphonates inhibit cell cycle progression in human melanoma cells. Br J Cancer 2004; 91: 803-810

15 Garbe C, Radny P, Linse R et al. Adjuvant low-dose interferon \{alpha\}2a with or without dacarbazine compared with surgery alone: a prospective-randomized phase III DeCOG trial in melanoma patients with regional lymph node metastasis. Ann Oncol 2008; 19: 11951201

16 Garbe $C$, Hauschild A, Volkenandt $M$ et al. Evidence and interdisciplinary consensus-based German guidelines: surgical treatment and radiotherapy of melanoma. Melanoma Res 2008; 18: 61 -67

17 Garbe C, Hauschild A, Volkenandt $M$ et al. Evidence and interdisciplinary consense-based German guidelines: diagnosis and surveillance of melanoma. Melanoma Res 2007; 17: 393 - 399

18 Garbe C, Eigentler TK. Diagnosis and treatment of cutaneous melanoma: state of the art 2006. Melanoma Res 2007; 17: $117-127$

19 Gille J. Antiangiogenic cancer therapies get their act together: current developments and future prospects of growth factor- and growth factor receptor-targeted approaches. Exp Dermatol 2006; 15: 175 186

20 Gniadecki R, Assaf C, Bagot $M$ et al. The optimal use of bexarotene in cutaneous T-cell lymphoma. Br J Dermatol 2007; 157: 433-440

21 Gogas H, Polyzos A, Stavrinidis I et al. Temozolomide in combination with celecoxib in patients with advanced melanoma.A phase II study of the Hellenic Cooperative Oncology Group. Ann Oncol 2006; 17: $1835-1841$

22 Hauschild A, Schadendorf D, Garbe $C$ et al. New promises in the adjuvant, and palliative treatment of melanoma. Cancer Treat Res 2007; 135: $277-292$

23 Hein $R$, Bosserhoff A, Ring J. Tumormarker beim malignen Melanom. Dtsch. Ärztebl 2006; : C771 - C774

24 Kim JJ, Goldie SJ. Health and economic implications of HPV vaccination in the United States. N Engl J Med 2008; 359: 821 - 832

25 Koyanagi K, Kuo C, Nagakawa T et al. Multimarker quantitative realtime PCR detection of circulating melanoma cells in peripheral blood: relation to disease stage in melanoma patients. Clin.Chem 2005; 51: 981 - 988

26 Kurbanov BM, Geilen CC, Fecker LZ et al. Efficient TRAIL-R1/DR4-mediated apoptosis in melanoma cells by tumor necrosis factor-related apoptosis-inducing ligand (TRAIL). J Invest Dermatol 2005; 125: $1010-1019$

27 Lasithiotakis K, Leiter U, Krüger-Krassagakis S et al. Comparative analysis of incidence and clinical features of cutaneous malignant melanoma in Crete (Greece) and southern Germany (central Baden-Württemberg). Br J Dermatol 2006; 154: 1123-1127

28 Leggatt GR, Fazer IH. HPV vaccines: The beginning of the end for cervical cancer. Curr Opin Immunol 2007; 19: 232 - 238

29 Leiter $U$, Garbe C. Epidemiology of melanoma and nonmelanoma skin cancer - the role of sunlight. Adv Exp Med Biol 2008; 624: 89-103

30 Lichon $V$, Khachemoune A. Xeroderma pigmentosum: beyond skin cancer. J Drugs Dermatol 2007; 6: 281 - 288

31 Mestel DS, Assaf C, Steinhoff $M$ et al. Emerging drugs in cutaneous T cell lymphoma. Expert Opin Emerg Drugs 2008; 13: 345 - 361

32 Molho-Pessach V, Lotem M. Ultraviolet radiation and cutaneous carcinogenesis. Curr Probl Dermatol 2007; 35: 14-27

33 Orfanos CE:Perspektiven der Dermatologie im 21. Jahrhundert. Hautarzt 2002; 53: $596-603$ 
34 Orfanos CE. HIV-Infektion in Afrika. Klinische Erfahrungen in der östlichen Sahara. Akt. Dermatol 2007; 33: 7-12

35 Orfanos CE, Husak R, Wölfer U, Garbe C. Kaposi's sarcoma: A reevaluation. Recent Results Cancer Res 1995; 139: 275-296

36 Pehamberger $H$. Perspectives of pegylated interferon use in dermatological oncology. Recent Results Cancer Res 2002; 160: 158 - 164

37 Potthoff A, Brockmeyer NH. HIV-assoziierte Tumoren. Hautarzt 2006; 57: 998, 990-993

38 Raisowa M, Eberle J, Hossini AM et al. The Bax/Bcl-2 ratio determines the susceptibility of human melanoma cells to CD95/Fas-mediated apoptosis. J Invest Dermatol 2001; 117: 333-340

39 Senff NJ, Noordijk NM, Kim YH et al. European Organization for Research and Treatment of Cancer and International Society for Cutaneous Lymphoma consensus recommendations for the management of cutaneous B-cell lymphomas. Blood 2008; 112: 1600- 1609

40 Stadler $R$. Interferons in dermatology. Present-day standard. Dermatol Clin 1998; 16: 377-398

41 Stadler $R$. Treatment of cutaneous T cell lymphoma. Skin Pharmacol Appl Skin Physiol 2002; 15: 139-146

42 Stadler R. Kutane Lymphome: Klassifikation und Stadium-adaptierte Therapie. Hautarzt 2006; 57: 744-755
43 Stadler R, Kremer A. Therapeutic advances in cutaneous T-cell lymphoma (CTCL): from retinoids to rexinoids. Semin Oncol 2006; 33 (Suppl 3): $7-10$

44 Stadler R, Otte HG. Combination therapy of cutaneous T cell lymphoma with interferon alpha-2a and photochemotherapy. Recent Results Cancer Res 1995; 139: $391-401$

45 Stratigos AJ, Dimisianos G, Nikolaou V et al. Melanocortin receptor-1 gene polymorphisms and the risk of cutaneous melanoma in a lowrisk southern European population. J Invest Dermatol 2006; 26: $1842-1849$

46 Tchernev G, Orfanos CE. Downregulation of cell cycle modulators p21, $\mathrm{p} 27, \mathrm{p} 53, \mathrm{Rb}$ and proapoptotic Bcl-2-related proteins Bax and Bak in cutaneous melanoma is associated with worse patient prognosis: preliminary findings. J Cutan Pathol 2007; 34: 247-256

47 Wamburu G, Masenga EJ, Moshi EZ et al. HIV-associated and non-HIV associated types of Kaposi's sarcoma in an African population in Tanzania. Status of immune suppression and HHV-8 seroprevalence. Eur J Dermatol 2006; 16: 677-682

48 Willemze R, Meiijer CJ. Classification of cutaneous T-cell lymphoma: from Alibert to WHO-EORTC. J Cutan Pathol 2006; 33 (Suppl 1): 18 26 